\title{
Shadow IT Use, Outcome Effects, and Subjective Performance Evaluation
}

\author{
Drew Allen \\ Brigham Young University \\ F. Greg Burton \\ Brigham Young University \\ Steven D. Smith \\ Brigham Young University \\ David A. Wood \\ Brigham Young University
}

Using shadow IT may be seen as either a form of organizational misbehavior or proactive and creative problem-solving. These perceptions have implications for the subjective evaluation of subordinate performance. In our experiment, participants choose whether to award a bonus to an employee when different IT systems are used across different outcome levels. We find that employees using shadow IT are less likely to receive the bonus in both high and low outcome conditions relative to employees using the normal IT system, suggesting that managers consider shadow IT usage an organizational misbehavior which casts a negative light on employee performance.

\section{INTRODUCTION}

The increasing use of shadow IT systems-IT applications not sanctioned or monitored by a company's IT department (Myers et al., 2016) - has emerged as an important topic for both practitioners and academics (Sherman, 2004; Raden, 2005; Olavsrud, 2012; Zimmerman, et al., 2017). ${ }^{1}$ Shadow IT systems can pose a threat to businesses because they often lack adequate security, effective controls, and proper documentation (Schaffner, 2007). Additionally, shadow IT systems can create opportunities for fraud and compromise the data integrity of authorized ERP systems (Raden, 2005; Uppatumwichian, et al., 2011; Guest and Bolger, 2012; Messmer, 2012; Kretzer and Maedche, 2014). However, employees often turn to shadow IT solutions because they offer more autonomy and flexibility than traditional ERP systems or other formalized IT applications (Behrens, 2009; Zimmerman et al., 2017). Because of the added flexibility, employees can often use shadow IT to craft solutions that are more efficient, targeted, and innovative than they otherwise would have been (Behrens, 2009). This creates a dilemma. Presumably, more efficient and innovative solutions benefit an organization in cost savings and competitive edge, both which enhance the bottom line; but because the use of shadow IT is not 
transparent and is outside the control of formal IT functions, companies struggle when employees use shadow IT (Zimmerman et al., 2017). Additionally, reluctance to embrace innovative solutions slows down the transfer and adoption of helpful technologies (Aguilar, et al., 2017).

Given these varying costs and benefits, it is unclear how managers view the use of shadow IT by employees. The use of shadow IT may be seen as a proactive step taken to solve a problem in a creative way (Zimmerman, et al., 2014). Alternatively, the use of shadow IT may be seen as a form of organizational misbehavior (Robinson and Bennett, 1995) and viewed in a negative light in performance evaluations (Rotundo and Sackett, 2002; Dunlop and Lee, 2004). Despite the potential benefits, a stigma against shadow IT persists in the workplace (Behrens, 2009). Prior research finds that managers are less willing to rely on reports generated from shadow IT systems than from non-shadow systems, suggesting that managers view these systems negatively (Myers et al., 2016). However, whether and how shadow IT usage affects managers' judgments remains an empirical question, and is the focus of our study.

We specifically consider how subordinate use of shadow IT systems impacts managers' performance evaluation judgments in the presence of outcome information. Given the competing costs and benefits of shadow IT usage, managers may be influenced by outcome information when forming their own opinions and evaluating performance. For example, a positive (negative) outcome achieved through the use of shadow IT could be used to justify perceptions of high (low) performance, supporting both high (low) evaluations and positive (negative) views of shadow IT usage.

We conduct a $2 \times 2$, between-subjects experiment in which participants choose the amount of an employee's bonus. We manipulate the type of IT system used by the employee (normal vs. shadow IT) and the favorability of the outcome (high vs. low operating profit margin). We then ask participants to evaluate the different factors that led to their bonus decisions and to evaluate the IT system across several dimensions. Subjective performance evaluations are a useful method of capturing opinions about shadow IT because they allow for individual discretion (Murphy and Oyer, 2003), leaving room for personal opinions and judgments to be observed (Murphy, et al., 1985; Lipe and Salterio, 2000; Bol and Smith, 2011).

We find that managers administer significantly lower bonus amounts to an employee who uses a shadow IT system than to an employee who uses the company-endorsed system. This result holds regardless of outcome favorability, suggesting that opinions toward shadow IT are not altered by outcome favorability. We also find that evaluators explicitly consider the system used by the employee and that, similar to Myers et al. (2016), shadow systems are viewed as less reliable than non-shadow IT systems. Thus, although shadow IT systems are prevalent in practice, we find that employees suffer negative consequences from their decision to use them.

Importantly, we find that evaluators differentially evaluate organizational and motivational skills based on outcome information. We also find that bonus amounts are significantly higher when there is a favorable work outcome for both shadow IT and non-shadow IT users. While our findings are consistent with prior evidence that outcomes play a significant role in how employees are evaluated (Brown and Solomon, 1987; Baron and Hershey, 1988; Lipe, 1993; Bol and Smith, 2011), we do not observe any interaction effect between outcomes and the use of shadow IT.

Our study contributes to the strategy and management literature in several ways. Management scholars have devoted significant efforts to understanding factors that affect performance evaluations (Tayler, 2010; Bol and Smith, 2011; Du et al., 2018). Although extensively studied, to our knowledge prior performance evaluation research has not examined how employees' use of technology affects the way they are evaluated. Thus, we expand the performance evaluation literature to study how the use of self-generated technology impacts performance evaluation.

Our study contributes to the emerging shadow IT literature by providing evidence that the use of shadow IT is likely to viewed negatively in subjective performance evaluations, regardless of work outcomes. This suggests that adherence to company IT rules and policies is weighted more heavily than positive outcomes in subjective evaluations and that managers have a negative attitude toward shadow IT despite its growing frequency. 
These findings may also partially explain why these systems are kept hidden. Since managers punish employees in their performance evaluations for the use of these systems, employees are incentivized to hide their creation and use of shadow IT systems, or to abandon the practice. Hiding shadow IT systems from management can be detrimental to an organization if these systems are also kept hidden from other stakeholders such as internal or external auditors. Hidden systems can expose companies to greater risk from negative events such as errors or security breaches. However, abandoning the use of shadow IT may constrain employees' abilities to operate creatively and efficiently. Thus, managers deliberating the costs and benefits of shadow IT may benefit from considering the behavioral implications of the performance evaluation results we document here.

The remainder of the paper proceeds as follows: the next sections review provide relevant background and develop our formal hypotheses. A description of the experimental methodology, a review of the results, and a summarizing conclusion follow.

\section{BACKGROUND}

Shadow IT use may take many different forms within an organization. One of the most common forms of shadow IT is the use of Software as a Service (SaaS) applications. In a recent survey, 80 percent of employees admitted to using these applications without approval (Stadtmueller, 2013). Other nonapproved forms of software use are possible, such as using spreadsheets in Microsoft Excel with information extracted from a company's ERP system to complete business tasks (Raden, 2005). The use of these types of software presents a problem for businesses because data from these applications can then be integrated with other enterprise applications without detection from the IT department (Guest and Bolger, 2012). Another form of shadow IT is the use of public cloud servers to store data. Darrow (2012) finds that 20 percent of business employees use public cloud servers (e.g., Dropbox, Google Drive, etc.) to store company documents. Finally, employees may operate outside of approved IT channels by performing work from their own devices - a practice known as "bring-your-own-device" (BYOD). Even though using an outside device at work creates the opportunity for workers to operate outside of IT department monitoring, many companies are beginning to embrace BYOD and even BYOA (bring-yourown-app) into their IT policies (Hinchcliffe, 2013).

Despite the numerous forms of shadow IT, the reasons these systems arise are often straightforward. Guest and Bolger (2012) write:

"The pressure on information workers to be productive outweighs any concerns over data security and corporate compliance. When staff need to access or share data quickly, they no longer need to rely on [the] IT [department] to provide the facility. Why would they go through the red tape of IT procurement, provisioning, testing, and security when they can find a solution themselves and be up and running in a matter of seconds?"

This statement is consistent with Stadtmueller (2013), who finds that 49 percent of users of nonapproved SaaS applications use these applications because they are more comfortable and more familiar with shadow IT applications. Those who use shadow spreadsheets in Excel do so because spreadsheets are expressive, allow for more autonomy, and are familiar to most users (Raden, 2005). Spreadsheets are also commonly used for forecasting when traditional ERP systems do not easily lend themselves to this function (Uppatumwichian et al., 2011). Other reasons for the emergence of shadow IT include limitations of the IT budget and deadline pressure (Smyth and Freeman, 2007).

In addition to the efficiency reasons for using shadow IT, some authors have suggested that shadow IT use enables creative and innovative business solutions that cannot be achieved through approved IT channels (Behrens, 2009; Rentrop and Zimmerman, 2012). Therefore, the use of shadow IT may be justifiable in instances where additional flexibility is needed beyond a company's IT systems. However, most of the discussion surrounding shadow IT continues to focus on its negative aspects. Although there are legitimate concerns surrounding the use of shadow IT, including loss of data integrity (Raden 2005; 
Uppatumwichian et al., 2011; Guest and Bolger, 2012), lack of controls (Behrens, 2009), and hazards to IT security (Walters, 2013), we argue there are sufficient compelling benefits from shadow IT use that managers could reasonably view the use of shadow IT in either a positive or negative light.

Little research has been conducted with the goal of understanding managers' perceptions of shadow IT use and factors that can affect those perceptions. Myers et al. (2016) report an experiment in which participants rate the reliability of reports generated from different IT systems. The study finds that reports generated by shadow systems are perceived as less reliable than those generated from traditional IT systems and that managers are less likely to incorporate data from shadow-generated reports into their decision-making. While these results suggest that shadow IT is perceived as less reliable than traditional IT systems, they do not provide evidence on employees who choose to use shadow IT are perceived by managers. Our study seeks to build upon the results of Myers et al. (2016) by examining how the use of shadow IT affects employee performance evaluations and how different work outcomes may alter the perceptions that managers have of employees who use shadow IT.

\section{HYPOTHESES}

While no prior research addresses our research question directly, several streams of research are useful in developing predictions for how shadow IT users will be evaluated. One such literature focuses on what is known as organizational misbehavior (OMB), described as an instance in which employees act against established organizational rules or norms (Robinson and Bennett, 1995; Vardi and Wiener, 1996; Rotundo and Sackett, 2002; Dunlop and Lee, 2004; Litzky, et al., 2006). ${ }^{2}$ Since shadow IT use represents a form of disobedience to organizational rules (using systems not approved or monitored by the IT department), the use of shadow IT can be viewed as a form of organizational misbehavior. Research in this field has generally found that OMB is negatively associated with perceived employee performance (Rotundo and Sackett, 2002; Dunlop and Lee, 2004). ${ }^{3}$ These studies support the idea that acting out against the rules and norms of an organization by using shadow IT will result in lower ratings on subjective performance evaluations, even when individuals have positive intentions. ${ }^{4}$

In contrast, research on what is known as the outcome effect predicts that perception of shadow IT use may vary according to the outcome achieved through shadow IT use. This research finds that outcomes impact employee evaluations, even when the evaluator has access to the employee's decision process (thus making outcome information irrelevant) and when evaluated factors are unrelated to the employee's work (Brown and Solomon, 1987; Baron and Hershey, 1988; Ghosh and Lusch, 2000; Bol and Smith, 2011). The outcome effect has also been found in situations where the outcome was not controllable by the employee (Tan and Lipe, 1997).

In the context of our study, this suggests that outcomes achieved through shadow IT use will influence the evaluator's perception of the employee's performance, and even of shadow IT in general. This claim is supported by anecdotal evidence that shadow IT users "... who attain stellar results are often praised for their willingness to take risks and "think outside the box"' (Stadtmueller, 2013, p.7). In other words, disobeying company rules through shadow IT use may result in higher performance evaluations if shadow IT use is accompanied by positive outcomes.

However, it is still unclear how evaluators will respond in scenarios where predictions based on outcome effects and organizational misbehavior conflict. The theory of cognitive dissonance is useful in these scenarios and suggests the possibility of a moderating relationship of work outcomes on the relationship between shadow IT use and performance evaluations. ${ }^{5}$ According to cognitive dissonance theory, individuals feel dissonance (psychological discomfort) when they hold cognitions that are opposed to each other and will seek to decrease that discomfort by reducing the dissonance between the cognitions (Festinger, 1957; Harmon-Jones and Mills, 1999). ${ }^{6}$ Cognitive dissonance is relevant to our study because shadow IT use and the outcomes achieved through shadow IT use are separate cognitions involved in the employee performance evaluation that may produce dissonance in certain scenarios. As previously discussed, research has shown that OMB is generally perceived negatively, and research on outcome effects has shown a strong positive effect for positive outcomes. Therefore, evaluating an 
employee that has used shadow IT in his or her work and has experienced a positive work outcome should produce dissonance in the evaluator.

In order to resolve this dissonance, the evaluator may choose to view shadow IT use in a positive light so that the cognitions from the positive work outcome and shadow IT use are in harmony with each other. This means that an evaluator will tend to have more positive cognitions for an employee that uses shadow IT and has a positive work outcome than for an employee that does not use shadow IT and has a positive outcome. In other words, the employee using shadow IT will receive a "premium" on their performance evaluation and will be evaluated higher than non-shadow IT users because the evaluator will have more positive cognitions associated with the employee using shadow IT than just the positive outcome alone.

However, a negative work outcome accompanied with shadow IT use should not produce cognitive dissonance within the evaluator. In this case, both the work outcome and shadow IT use will be perceived negatively. Both cognitions are consonant with each other and will not cause the evaluator to feel psychologically uncomfortable. Additionally, because both cognitions are negatively perceived, the employee who uses shadow IT and has a negative outcome will have a lower performance evaluation than an employee who does not use shadow IT and has a negative outcome because the shadow IT user will be "punished" for those negative cognitions related to shadow IT use. Therefore, we predict an interaction between outcome favorability and shadow IT use. To state our predictions formally:

Hypothesis 1: Employee performance evaluations will be higher when there is a positive outcome than when there is a negative outcome.

Hypothesis 2: Employee performance evaluations will be higher for employees who use shadow IT and have a positive work outcome than for employees who do not use shadow IT and have a positive work outcome.

Hypothesis 3: Employee performance evaluations will be lower for employees who use shadow IT and have a negative work outcome than for employees who do not use shadow IT and have a negative work outcome.

\section{METHODOLOGY}

To test our hypotheses, we conduct a $2 \times 2$ between-subjects experiment, manipulating the IT system used and the favorability of the work outcome achieved. The experimental task involves participants, in the role of manager, conducting a subjective performance evaluation of a subordinate employee, with both IT usage and outcome favorability known.

Participants

We recruited participants for this study from a pool of various business school classes held at a large, private university in the western United States. All participants received extra credit for participating. Table 1 presents demographic information. Participants were of diverse class standing, age (within the student population demographic), and gender. There were no significant differences in results across various demographic measures. While our participants are not current working professionals, participants had on average 2.5 years of work experience and over 90 percent had at least some work experience. Furthermore, if we include experience as a covariate in all of our models it does not load significantly or change the results. Also, if we delete participant observations if they had no experience it does not change our result. This suggests that using more experienced professionals would not change the inferences from our findings. Thus, it is unlikely that we would find different results using experienced professionals. 
TABLE 1

\section{PARTICIPANT DEMOGRAPHICS}

\begin{tabular}{lcc}
\hline Variable & Mean & Stdev \\
\hline Age & 22.4 & 3.0 \\
\% Male & $64 \%$ & $48 \%$ \\
GPA & 3.61 & 0.40 \\
Total Experience (in years) & 2.5 & 2.1 \\
Class Standing & & \\
$\quad$ Freshman & $52(10 \%)$ & \\
$\quad$ Sophmore & $145(28 \%)$ & \\
$\quad$ Junior & $169(32 \%)$ & \\
$\quad$ Senior & $98(19 \%)$ & \\
$\quad$ Masters (MBA, MAcc, etc.) & $61(12 \%)$ & \\
\hline
\end{tabular}

A total of 526 participants responded (not all participants responded to each question). For the total experience variable, one participant responded they had 138 years of experience. This value was winzoried to the next highest years of experience (10 years).

\section{Procedure}

Participants completed a subjective performance evaluation for one employee while acting as the regional director of a hypothetical company. We adapted the instrument from Bol and Smith (2011) for our study. In the case, we asked participants to determine what percentage (between 0 and 33 percent) of the employee's base salary should be administered as a bonus. In making this decision, participants were told that their decision should be "partially based on the store's operating profit (relative to target)" (emphasis as in the instrument), but that they should also "consider other factors that you believe are related to the manager's performance." We did this to allow for subjectivity in the performance evaluation. Without explicit criteria for how to administer the bonus, participants had to rely on their own judgments and opinions to make this subjective decision.

After reading an overview of the task, we gave participants basic information about the hypothetical manager they would be evaluating, including the employee's name, age, experience at the company, and salary. Additionally, we displayed information relating to the manager's store performance, including operating profit, operating profit goal, and the percentage of operating profit goal that was realized. Following this objective data, we showed participants various comments about the employee, including a note about the type of IT system used by the employee, a note commenting on the employee's punctuality, and notes describing the employee's overall demeanor. These were meant to inform the subjective portion of the evaluation.

Once participants had read the information and assigned a bonus percentage to the employee, we concluded the experiment by having participants answer a series of survey questions. The first set of questions addressed the different factors that went into each participant's bonus decision. ${ }^{7}$ Another set of questions asked how participants felt about the IT system used by the employee. ${ }^{8}$ Finally, participants answered two manipulation check questions to ensure that they understood the store's performance relative to its operating profit goal and the type of IT system used by the employee (participants were removed if they failed the manipulation check questions).

\section{Independent Variables}

We randomly assigned participants to one of four different conditions that resulted from the crossing of a shadow IT manipulation (shadow IT or no shadow IT) with a work outcome manipulation (high performance or low performance). The first independent variable is the type of IT system used by the 
manager being evaluated. To manipulate this variable, we changed the wording of one of the notes included in the data used to help participants make their bonus decision. The wording of the shadow IT and non-shadow IT conditions is as follows:

Shadow IT: You learn that during 2015 David developed a small information system for use in his store. The system David uses includes integrated spreadsheets and file sharing software to gather and share information about sales, expenses, inventory, personnel, etc. The self-developed system is not approved and monitored by the company's IT personnel. Company policy requires that employees use systems and technologies that have been approved by IT personnel.

Non-shadow IT: You learn that during 2015 David used the corporate information system in his store. The system David uses includes integrated spreadsheets and file sharing software to gather and share information about sales, expenses, inventory, personnel, etc. The corporate system is approved and monitored by the company's IT personnel. Company policy requires that employees use systems and technologies that have been approved by IT personnel.

The second independent variable is the work outcome achieved by the manager in the evaluation. To manipulate this variable, we alter the store's profit margin goal so that it is either 17 percent higher or lower than the store's actual profit margin for the year. There is a favorable outcome when the store has exceeded its profit margin goal and an unfavorable outcome when the store has failed to meet its profit margin goal.

\section{Dependent Variables}

Our primary dependent variable is the percentage of the employee's salary that participants awarded as a bonus. A higher (lower) bonus amount indicates a more positive (negative) view of the employee. Our other dependent variables consist of answers to the previously mentioned survey questions, with higher numbers indicating stronger agreement with a statement or greater acknowledgement of the importance of a given factor in determining the bonus.

\section{RESULTS AND DISCUSSION}

After eliminating responses from participants who failed to correctly answer both of the manipulation check questions, we were left with 526 responses. ${ }^{9}$ Table 2 contains descriptive statistics and the analysis of how bonuses were awarded in our experiment.

\section{Test of Hypotheses}

H1 predicts the basic outcome effect - that evaluations (i.e., bonus amounts) will be higher (lower) when outcomes are favorable (unfavorable). $\mathrm{H} 2$ and $\mathrm{H} 3$ combined predict an interaction effect - that is, employees who use shadow IT will be rewarded (punished) when performance is high (low) relative to non-shadow IT users. Panel B of Table 2 provides an ANOVA test of the predicted interaction. We find that outcome favorability has a significant main effect $(\mathrm{p}<0.001)$; participants awarded a higher bonus for a favorable outcome (mean bonus of 15.86 percent) than for an unfavorable outcome (mean bonus of 11.13 percent). Thus, we find support for H1. Shadow IT use also has a significant main effect ( $\mathrm{p}=$ 0.013); participants awarded a higher bonus when the employee used a non-shadow IT system (mean bonus of 14.29 percent) than when the employee used a shadow IT system (mean bonus of 13.22 percent). However, the interaction effect is not statistically significant ( $\mathrm{p}$-value $=0.383$ ).

When we separately analyze $\mathrm{H} 2$ and $\mathrm{H} 3$, we find that the results are consistent with half of the interaction effect. That is, H3 predicts that participants would reward a lower bonus for a shadow IT system when there is low performance. The results in Panel A show a marginally significant effect (p- 
value $=0.084$ ). In contrast, $\mathrm{H} 2$ predicts that participants would reward a larger bonus for a shadow IT system when there was a positive outcome. The results show that this is not the case, as participants still punished the employee who used the shadow IT system in the positive outcome condition ( $\mathrm{p}$-value $=$ 0.069). Thus, the results suggest that participants respond negatively to shadow, regardless of the favorability of observed outcomes.

TABLE 2

ANALYSIS OF BONUSES AWARDED

Panel A: Percentage awarded as a Bonus

\begin{tabular}{lccccc} 
Mean $(\mathrm{Std})[\mathrm{n}]$ & Shadow IT & Non-Shadow IT & Marginal Means & T-stat & P-value \\
\hline Low Performance & $10.53(6.01)[110]$ & $11.66(6.45)[124]$ & $11.13(6.26)[234]$ & 1.39 & 0.084 \\
High Performance & $15.16(7.18)[153]$ & $16.64(6.69)[139]$ & $15.86(6.98)[292]$ & 1.83 & 0.069 \\
Marginal Means & $13.22(7.08)[263]$ & $14.29(7.02)[263]$ & & & \\
T-stat & -5.68 & -6.14 & & \\
P-value & $<0.001$ & $<0.001$ & & \\
\hline
\end{tabular}

Panel B: Multivariate Tests of How Shadow IT and Performance Impact Bonus

\begin{tabular}{lccc} 
Variable & Sum of Squares & F-value & P-value \\
\hline Shadow IT & 221.82 & 5.02 & 0.013 \\
HighPerformance & $2,989.25$ & 67.66 & $<0.001$ \\
Shadow IT * HighPerformance & 3.95 & 0.09 & 0.383 \\
\hline
\end{tabular}

P-values are one-tailed when a directional prediction is made and the results are consistent with the prediction. Reported values are the answer to the question, "Please provide your choice for the bonus David Sutton should receive. Remember that David's annual bonus can range from $0 \%$ to $33 \%$ of his annual salary of $\$ 64,000$." Participants then used a slider to indicate a whole number between 0 and 33. The Low and High Performance variables represent whether operating profit was below or above the target profit, respectively. Shadow IT and Nonshadow IT variables represent whether the participants were in the condition where the store manager used a shadow IT system or a non-shadow IT system, respectively.

To shed additional light on the effects of shadow IT on performance evaluations, we analyze additional post-experimental questions. Table 3 shows the weights participants claimed to place on different factors in their bonus decisions. We note several interesting results. First, we find a significant negative effect for how participants view the type of system used (p-value $<0.01$ ). In both positive and negative outcome conditions, participants viewed the use of shadow IT more negatively than the use of the non-shadow IT. This result is consistent with participants' bonus awards and provides additional evidence that participants view the use of shadow IT negatively. We do note there is a marginally significant interaction ( $\mathrm{p}$-value $<0.10$ ), which shows that the differences in bonuses for the two performance conditions were greater for non-shadow IT than for shadow IT. In other words, performance had a smaller effect on the perception of shadow IT use than it did on the perception of non-shadow IT use.

Second, we find that performance did impact how most of the various other performance factors were perceived. Type of system used, organizational skills, and motivational skills were each appraised more positively when performance was higher (p-values $<0.01$ ). ${ }^{10}$ Thus, we do observe outcome effects - the same information is interpreted more favorably when operating performance is high than when it is low.

Third, we find that the shadow IT manipulations do not have a main or interactive effect on how the other factors are evaluated (all p-values $>0.10$ ). Thus, unlike work outcomes, the use of shadow IT does 
not create an outcome effect in which non-related factors are evaluated differently based on the IT system used. Rather, participants view shadow IT use negatively, but do not let the choice to use shadow IT impact assessments of organizational, interpersonal, and motivational skills.

TABLE 3

PERCEPTIONS OF HOW VARIOUS FACTORS IMPACT THE BONUS DECISION

\begin{tabular}{|c|c|c|c|c|c|c|c|}
\hline & \multicolumn{2}{|c|}{ Low Performance } & \multicolumn{2}{|c|}{ High Performance } & \multicolumn{3}{|c|}{ F-tests (f-values are presented) } \\
\hline Mean (Stdev) & $\begin{array}{c}\text { Shadow } \\
\text { IT }\end{array}$ & $\begin{array}{c}\text { Non-Shadow } \\
\text { IT }\end{array}$ & $\begin{array}{l}\text { Shadow } \\
\text { IT }\end{array}$ & $\begin{array}{c}\text { Non- } \\
\text { Shadow IT }\end{array}$ & $\begin{array}{l}\text { Shadow } \\
\text { IT }\end{array}$ & $\begin{array}{c}\text { Per- } \\
\text { formance }\end{array}$ & $\begin{array}{l}\text { Inter- } \\
\text { action }\end{array}$ \\
\hline Type of system used & $\begin{array}{l}-0.17 \\
(1.68)\end{array}$ & $\begin{array}{c}0.58 \\
(1.22)\end{array}$ & $\begin{array}{c}0.08 \\
(1.83)\end{array}$ & $\begin{array}{c}1.29 \\
(1.16)\end{array}$ & $54.85 * * *$ & $13.10 * * *$ & $2.94 *$ \\
\hline 2015 operating profit & $\begin{array}{l}-0.25 \\
(1.74)\end{array}$ & $\begin{array}{c}-0.45 \\
(1.93)\end{array}$ & $\begin{array}{c}2.03 \\
(1.06)\end{array}$ & $\begin{array}{c}2.12 \\
(1.08)\end{array}$ & 0.17 & $353.68 * * *$ & 1.36 \\
\hline $\begin{array}{l}\text { David's organizational } \\
\text { skills }\end{array}$ & $\begin{array}{l}-0.98 \\
(1.21)\end{array}$ & $\begin{array}{l}-1.00 \\
(1.29)\end{array}$ & $\begin{array}{l}-0.48 \\
(1.33)\end{array}$ & $\begin{array}{l}-0.60 \\
(1.41)\end{array}$ & 0.36 & $14.81 * * *$ & 0.19 \\
\hline $\begin{array}{l}\text { David's interpersonal } \\
\text { skills }\end{array}$ & $\begin{array}{c}0.33 \\
(1.19)\end{array}$ & $\begin{array}{c}0.36 \\
(1.21)\end{array}$ & $\begin{array}{c}0.54 \\
(1.22)\end{array}$ & $\begin{array}{c}0.46 \\
(1.26)\end{array}$ & 0.04 & 1.98 & 0.25 \\
\hline $\begin{array}{l}\text { David's motivational } \\
\text { skills }\end{array}$ & $\begin{array}{c}0.27 \\
(1.30)\end{array}$ & $\begin{array}{c}0.42 \\
(1.35)\end{array}$ & $\begin{array}{c}0.64 \\
(1.29)\end{array}$ & $\begin{array}{c}0.76 \\
(1.13)\end{array}$ & 1.53 & $10.37^{* * *}$ & 0.02 \\
\hline
\end{tabular}

P-values are one-tailed when a directional prediction is made and the results are consistent with the prediction. Reported values are the answer to the question, "How did the following aspects of David Sutton's work influence your bonus granting decision?" The sub-questions were presented in a random order and participants answered on a 7-point scale anchored at -3 , significantly decreased his bonus; 0 , did not impact his bonus; and 3, significantly increased his bonus. F-tests are from separate ANOVAs conducted using the variables performance, shadow IT, and their interaction.

Given that relatively little academic work examines shadow IT, we also asked for participants' perception of reports created using shadow IT. We report the results in Table 4. We again disaggregate the results by the type of system used and outcome favorability. We note that reports prepared from a shadow IT system are viewed as less accurate ( $p$-value $<0.01$ ), less complete ( $p$-value $<0.01$ ), more likely to contain mistakes ( $\mathrm{p}$-value $<0.01$ ), more likely to be fraudulently manipulated ( $\mathrm{p}$-value $<0.01$ ), less easy to produce ( $p$-value $<0.10)$, and less useful ( $p$-value $<0.01)$ than a report prepared using a nonshadow IT system. These findings support the findings of Myers et al. (2016), who conclude that managers view shadow IT as less reliable than traditional ERM systems. Similar to the results in Table 3, we also observe that performance creates outcome effects whereby participants assess the reports more positively if the employee had high performance. With the exception of a marginally significant interaction effect on the "mistakes" variable, we do not observe significant interaction effects of shadow IT and performance-again suggesting that participants view shadow IT negatively, even when performance is high. 
TABLE 4

PERCEPTIONS OF SHADOW IT USE BASED ON PERFORMANCE

\begin{tabular}{|c|c|c|c|c|c|c|c|}
\hline \multirow[b]{2}{*}{$\begin{array}{c}\text { Mean } \\
\text { (Stdev) }\end{array}$} & \multicolumn{2}{|c|}{ Low Performance } & \multicolumn{2}{|c|}{ High Performance } & \multicolumn{3}{|c|}{ F-tests (f-values are presented) } \\
\hline & Shadow IT & $\begin{array}{l}\text { Non- } \\
\text { Shadow } \\
\text { IT }\end{array}$ & $\begin{array}{l}\text { Shadow } \\
\text { IT }\end{array}$ & $\begin{array}{l}\text { Non- } \\
\text { Shadow IT }\end{array}$ & Shadow IT & Performance & Interaction \\
\hline Accurate & $\begin{array}{c}-0.17 \\
(1.21)\end{array}$ & $\begin{array}{c}0.48 \\
(1.35)\end{array}$ & $\begin{array}{c}0.10 \\
(1.21)\end{array}$ & $\begin{array}{c}0.68 \\
(1.28)\end{array}$ & $29.78 * * *$ & $4.48 * *$ & 0.10 \\
\hline & -0.21 & 0.32 & 0.02 & 0.60 & & & \\
\hline Complete & $\begin{array}{c}(1.26) \\
1.02\end{array}$ & $\begin{array}{c}(1.48) \\
0.75\end{array}$ & $\begin{array}{c}(1.35) \\
1.01\end{array}$ & $\begin{array}{c}(1.25) \\
0.35\end{array}$ & $22.49 * * *$ & $4.72 * *$ & 0.05 \\
\hline Mistakes & (1.13) & (1.29) & (1.16) & $(1.27)$ & $19.18 * * *$ & $3.68 * *$ & $3.49 *$ \\
\hline Fraudulently & & 0.28 & 1.25 & 0.17 & & & \\
\hline Manipulated & $1.18(1.18)$ & $(1.42)$ & (1.37) & (1.39) & $69.63 * * *$ & 0.05 & 0.58 \\
\hline Easy to & & 0.33 & 0.19 & 0.41 & & & \\
\hline Produce & $0.15(1.35)$ & $\begin{array}{c}(1.42) \\
1.27\end{array}$ & $\begin{array}{c}(1.29) \\
1.03\end{array}$ & $\begin{array}{c}(1.29) \\
1.52\end{array}$ & $2.96^{*}$ & 0.27 & 0.02 \\
\hline Useful & $0.78(1.12)$ & $(1.14)$ & $(1.23)$ & $(1.11)$ & $22.93 * * *$ & $6.19 * * *$ & 0.00 \\
\hline
\end{tabular}

P-values are one-tailed when a directional prediction is made and the results are consistent with the prediction. Reported values are the answer to the question, "Please answer the following questions concerning David Sutton's use of the information system to gather and share information about sales, expenses, inventory, personnel, etc. Please indicate whether you disagree or agree with the following statements." The sub-question (asked as "Reports from the system will be ___ were presented in a random order and participants answered on a 7 point scale anchored at -3 , strongly disagree; -2 disagree; -1 , somewhat disagree; 0 , neither agree nor disagree; 1 , somewhat agree; 2, agree; and 3, strongly agree. F-tests are from separate ANOVAs conducted using the variables performance, shadow IT, and their interaction.

\section{CONCLUSION}

In this paper we examine how the use of shadow IT systems impacts managers' subjective performance evaluations. While we predict that managers will perceive shadow IT favorably if an employee has high performance and negatively if an employee has low performance, the evidence suggests that shadow IT use is uniformly associated with lower bonus amounts and negative perceptions.

There are several important observations to be made from these results. First, our evidence indicates that an evaluator's opinion on shadow IT may be unaffected by the work outcome achieved from using shadow systems. This is important because it suggests that those charged with performing evaluations may be so concerned with enforcing current company rules and norms that they are unwilling to embrace new IT solutions that could actually improve firm operations and outcomes. If a positive work outcome cannot alter the way that shadow systems are viewed, it is possible that attitudes against shadow IT may be even more deeply entrenched in today's working world than we originally anticipated.

In the context of the cognitive dissonance framework used to develop our hypotheses, this suggests that the use of shadow IT may be a more basic cognition then we expected and that a favorable work outcome accompanied by the use of shadow IT may not produce a significant level of dissonance within an evaluator. In all situations we examined, participants viewed shadow IT negatively. This is consistent with the organizational misbehavior literature, which has repeatedly shown that even when employees have positive intentions, actions outside of a company's rules and norms are punished (Rotundo and Sackett, 2002; Dunlop and Lee, 2004; Dahling et al., 2012).

Our research is subject to the normal limitations of experimental research. In addition, we highlight additional limitations and suggestions for future research. First, we did not explicitly tie the use of shadow IT to performance in our instrument. That is, we did not indicate that the use (or non-use) of shadow IT is what caused the high or low performance. It would be interesting for future research to examine whether our results hold in a situation where the shadow IT was the cause of the performance outcome. Second, this study, combined with Myers et al. (2016), shows that there are relatively negative 
perceptions of shadow IT and there are costly effects to its use. This study does not study why employees use shadow IT despite these negatives. Future research should study why people use shadow IT answering such questions as whether they understand how it is perceived, how it influences organizations, etc. Additionally, future research should continue to build on the work of Zimmerman, et al. (2017) and Walterbusch, et al. (2017) who suggest ways that organizations can manage shadow IT to their benefit. Finally, we use a generic manipulation of shadow IT-describing the definition of shadow IT but not mentioning specific technologies. Myers et al. (2016) perform a similar manipulation but also study one type of shadow IT, rogue spreadsheet use. It would be beneficial to understand if all types of shadow IT are viewed the same and what factors might influence shadow IT perceptions. For example, how is it perceived if the company does not have current IT capabilities and employees develop shadow IT to fulfill a need? Do prior negative/positive experiences with the IT department (or with tools approved and monitored by the IT department) influence how shadow IT is perceived? Does the sophistication of the IT and of the decision setting impact the perception of shadow IT?

Given the extensive use of and projected growth in shadow IT, we believe this is an important topic that will require additional research going forward to understand the full implications of this new technological trend.

\section{ENDNOTES}

1. The definition from Myers et al. (2016) is similar to that of Rentrop and Zimmermann (2012) who define Shadow IT as "a collection of systems developed by business departments without support of the official IT department" (pg. 100).

2. This literature has specifically named three types of OMB: S-OMB, which is OMB meant to benefit the self-interest of the individual perpetrating the OMB; O-OMB, which is OMB which is meant to benefit the organization rather than the individual; and D-OMB, which is OMB meant to inflict damage on others or the organization (Vardi and Wiener 1996). Shadow IT use could plausibly belong to any of the three categories: an employee may feel that using shadow IT can benefit the organization by improving efficiency (O-OMB), or an employee may use shadow IT to seek after bonuses/promotions (S-OMB), or an employee could use it to sabotage the IT department (D-OMB).

3. While these results provide a useful starting point, it is worth noting that these studies focused on the effects of the more damaging forms of workplace deviance (i.e., S-OMB and D-OMB) on performance evaluation rather than forms of OMB that could potentially benefit an organization (i.e., O-OMB). For this reason, it is difficult to say if the use of shadow IT use would produce these same results on an employee performance evaluation.

4. Another branch of organizational behavior research addresses the topic of pro-social rule breaking (PSRB), which is described as instances in which employees deliberately go against formal company policy, rules, or prohibitions with the intention of promoting the welfare of the organization (Puffer, 1987; Morrison, 2006; Dahling, et al., 2012). Dahling et al. (2012) find that despite the positive intentions that accompany pro-social rule breaking, both supervisors and coworkers perceive PSRB negatively.

5. Cognitive dissonance has been demonstrated in numerous studies over time and continues to be a fruitful area of study in the psychological sciences (Jermias, 2001; Birnberg, et al., 2006; Harmon-Jones and Harmon-Jones, 2008; Jarcho, et al., 2011).

6. Festinger (1957) proposed the dissonance ratio in which the amount of dissonance one feels is equal to the number of dissonant cognitions divided by the number of consonant plus the number of dissonant cognitions. In order to reduce the dissonance, the individual must decrease the number of dissonant cognitions or increase the number of consonant cognitions (Festinger and Carlsmith, 1959; Harmon-Jones and Mills, 1999)

7. These questions asked subjects to rate how different factors affected their bonus granting decision using a 7-point Likert scale anchored at -3 (significantly decreased his bonus), 0 (did not impact his bonus), and 3 (significantly increased his bonus). The factors listed included the store's operating profit, the information system used by the employee, the employee's organizational skills, the employee's interpersonal skills, and the employee's motivational skills. 
8. We asked subjects to evaluate the degree they agreed or disagreed with different statements relating to the IT system described in the experiment using a 7-point Likert scale anchored at 1 (completely disagree) and 7 (completely agree). These statements asked if participants agreed/disagreed that reports generated from the system described would be accurate, if the reports would be complete, if the reports were likely to contain mistakes, if the reports were prone to fraudulent manipulation, if producing new types of reports would be easy for the system, and if reports from the system would be useful and informative for decision making.

9. One hundred and twenty-five participants missed the manipulation check questions (19.2 percent of the sample). Upon further examination, every participant answered the manipulation check question about shadow IT correctly. All participants missed the question about whether the store operating profit was above or under target. Thus, we are confident that participants attended to our Shadow IT manipulation. Although the failure rate is relatively high for the performance manipulation, it is in line with some other studies that use students and subtle manipulations (e.g., see Bartlett et al. 2016a, 2016b; see experiment 2 in Myers et al. 2016).

10. We also note that the operating profit was perceived more positively in the high performance condition. This suggests that even though we had a high manipulation check failure for the performance measure, this variable still successfully manipulated performance in the minds of the majority of our participants.

\section{REFERENCES}

Aguilar, I., Mertens, D., \& Shelton, P. (2017). Technology transfer versus transformation. Journal of Strategic Innovation and Sustainability, 12(2), 75-84.

Baron, J., \& Hershey, J. C. (1988). Outcome bias in decision evaluation. Journal of Personality and Social Psychology, 54(4), 569-579.

Behrens, S. (2009). Shadow systems: the good, the bad and the ugly. Communications of the ACM, 52(2), $124-129$.

Bol, J. C., \& Smith, S. D. (2011). Spillover Effects in Subjective Performance Evaluation: Bias and the Asymmetric Influence of Controllability. The Accounting Review, 86(4), 1213-1230.

Brown, C. E., \& Solomon, I. (1987). Effects of Outcome Information on Evaluations of Managerial Decisions. The Accounting Review, 62(3), 564-577.

Dahling, J. J., Chau, S. L., Mayer, D. M., \& Gregory, J. B. (2012). Breaking rules for the right reasons? An investigation of pro-social rule breaking. Journal of Organizational Behavior, 33(1), 21-42.

Darrow, B. (2012). Guess what Mr. CIO? One in five of your employees uses Dropbox at work. GigaOM. Available at: https://gigaom.com/2012/12/02/guess-what-mr-cio-one-in-five-of-your-employeesuse-dropbox-for-work-files/

Du, F., Erkens, D. H., Young, S. M., \& Tang, G. (2018). How Adopting New Performance Measures Affects Subjective Performance Evaluations: Evidence from EVA Adoption by Chinese StateOwned Enterprises. The Accounting Review, 93(1), 161-185.

Dunlop, P. D., \& Lee, K. (2004). Workplace Deviance, Organizational Citizenship Behavior, and Business Unit Performance: The Bad Apples Do Spoil the Whole Barrel. Journal of Organizational Behavior, 25(1), 67-80.

Festinger, L. (1957). A Theory of Cognitive Dissonance. Evanston, IL: Row, Peterson.

Festinger, L., \& Carlsmith, J. (1959). Cognitive Consequences of Forced Compliance. Journal of Abnormal and Social Psychology, 58(2), 203-210.

Ghosh, D., \& Lusch, R. F. (2000). Outcome effect, controllability and performance evaluation of managers: some field evidence from multi-outlet businesses. Accounting, Organizations and Society, 25(4-5), 411-425.

Guest, V., \& Bolger, P. (2012). Managing shadow IT. ComputerWeekly. Available at: http://www.computerweekly.com/opinion/Managing-shadow-IT.

Harmon-Jones, E., \& Harmon-Jones C. (2008). Action-Based Model of Dissonance: A Review of Behavioral, Anterior Cingulate, and Prefrontal Cortical Mechanisms. Social and Personality Psychology Compass, 2(3), 1518-1538. 
Harmon-Jones, E., \& Mills, J. (1999). An Introduction to Cognitive Dissonance Theory and an Overview of Current Perspectives on the Theory. In Cognitive Dissonance: Progress on a Pivotal Theory in Social Psychology, ed. E. Harmon-Jones and J. Mills, 3-21. Washington, DC: American Psychological Association.

Hinchcliffe, D. (2013). Digital diaspora in the enterprise: Arrival of the CDO and CCO. ZDNet. Available at: http://www.zdnet.com/article/digital-diaspora-in-the-enterprise-arrival-of-the-cdo-and-cco/.

Jarcho, J. M., Berkman, E. T., \& Lieberman, M. D. (2011). The neural basis of rationalization: cognitive dissonance reduction during decision-making. Social Cognitive and Affective Neuroscience, 6(4), $460-467$.

Jermias, J. (2001). Cognitive dissonance and resistance to change: the influence of commitment confirmation and feedback on judgment usefulness of accounting systems. Accounting, Organizations and Society, 26(2), 141-160.

Kretzer, M., \& Maedche, A. (2014). Generativity of Business Intelligence Platforms: A Research Agenda Guided by Lesson from Shadow IT. In Multikonferenz Wirtschaftsinformatik, 207-220. Available at: http://ub-madoc.bib.uni-mannheim.de/35583/1/KretzerMaedche2014_-

BI_Platform_Generativity\%2C_Shadow_IS_\%28MKWI\%29.pdf.

Lipe, M. G. (1993). Analyzing the variance investigation decision: The effects of outcomes, mental accounting, and framing. The Accounting Review, 68(4), 748.

Lipe, M. G., \& Salterio, S. E. (2000). The balanced scorecard: Judgmental effects of common and unique performance measures. The Accounting Review, 75(3), 283-298.

Litzky, B. E., Eddleston, K. A., \& Kidder, D. L. (2006). The Good, the Bad, and the Misguided: How Managers Inadvertently Encourage Deviant Behaviors. The Academy of Management Perspectives, 20(1), 91-103.

Messmer, E. (2012). Does "shadow IT" lurk in your company? Network World Fusion. Available at: http://www.networkworld.com/article/2190415/infrastructure-management/does--shadow-it-lurk-in-your-company-.html.

Morrison, E. W. (2006). Doing the Job Well: An Investigation of Pro-Social Rule Breaking. Journal of Management, 32 (1), 5-28.

Murphy, K. J., Balzer, W. K., Lockhart, M. C., \& Eisenman, E. J. (1985). Effects of previous performance on evaluations of present performance. Journal of Applied Psychology, 70(1), 72 84.

Murphy, K. J., \& Oyer, P. (2003). Discretion in executive incentive contracts: Theory and evidence. Working paper, University of Southern California and Stanford University.

Myers, N., Starliper, M. W., Summers, S. L., \& Wood, D. A. (2016). The Impact of Shadow IT Systems on Perceived Information Credibility and Managerial Decision Making. Accounting Horizons, 31(3), 105-123.

Olavsrud, T. (2012). Embrace Consumerization of IT and Stop Saying No. CIO. Available at: http://www.cio.com/article/718585/Embrace_Consumerization_of_IT_and_Stop_Saying_No.

Puffer, S. M. (1987). Prosocial Behavior, Noncompliant Behavior, and Work Performance Among Commission Salespeople. Journal of Applied Psychology, 72(4), 615-621.

Raden, N. (2005). Shedding Light on Shadow IT: Is Excel Running Your Business? Hired Brains, Inc. Available at: http://dssresources.com/papers/features/raden/raden02262005.html.

Rentrop, C., \& Zimmermann, S. (2012). Shadow IT - Management and Control of Unofficial IT. In ICDS 2012, The Sixth International Conference on Digital Society, 98-102.

Robinson, S. L., \& Bennett, R. J. (1995). A Typology of Deviant Workplace Behaviors: A Multidimensional Scaling Study. The Academy of Management Journal, 38(2), 555-572.

Rotundo, M., \& Sackett, P. R. (2002). The relative importance of task, citizenship, and counterproductive performance to global ratings of job performance: A policy-capturing approach. Journal of Applied Psychology, 87(1), 66-80. 
Schaffner, M. (2007). IT Needs to Become More Like Shadow IT. Beyond Blinking Lights and Acronyms. Available at:

http://mikeschaffner.typepad.com/michael_schaffner/2007/01/we_need_more_sh.html

Sherman, R. (2004). Shedding Light on Data Shadow Systems. Information Management Online. Available at: http://www.information-management.com/news/1002617-1.html.

Smyth, K., \& Freeman, J. (2007). Blue Prism Rogue IT Survey 2007. Blue Prism, 1-5.

Stadtmueller, L. (2013). The Hidden Truth Behind Shadow IT: Six Trends Impacting Your Security Posture. Stratecast and Frost \& Sullivan. Available at: http://www.mcafee.com/us/resources/reports/rp-six-trends-security.pdf.

Tan, H.-T., \& Lipe, M. G. (1997). Outcome effects: The impact of decision process and outcome controllability. Journal of Behavioral Decision Making, 10(4), 315-325.

Tayler, W. B. (2010). The Balanced Scorecard as a Strategy-Evaluation Tool: The Effects of Implementation Involvement and a Causal-Chain Focus. The Accounting Review, 85(3), 10951117.

Uppatumwichian, W., Johansson, B., \& Carlsson, S. (2011). Accounting Solutions Use For Budgeting In ERP, Hybrid ERP And BoB: An Explorative Study. PACIS 2011 Proceedings.

Vardi, Y., \& Wiener, Y. (1996). Misbehavior in Organizations: A Motivational Framework. Organization Science, 7(2), 151-165.

Walterbusch, M., Fietz, A., \& Teuteberg, F. (2017). Missing cloud security awareness: investigating risk exposure in shadow IT. Journal of Enterprise Information Management, 30(4), 644-665.

Walters, R. (2013). "Bringing IT out of the shadows". Network Security, 4, 5-11.

Zimmermann, S., Rentrop, C., \& Felden, C. (2014). Managing Shadow IT Instances - A method to control autonomous IT solutions in the business departments; In Proceedings of the 20th Americas Conference on Information Systems (AMCIS). Savannah, Georgia, 1-12.

Zimmermann, S., Rentrop, C., \& Felden, C. (2017). A Multiple Case Study on the Nature and Management of Shadow Information Technology. Journal of Information Systems, 31(1), 79-101. 